\title{
Prolonged nasogastric tube feeding in critically ill and surgical patients
}

\author{
A. M. J. WoOLFSON* \\ M.B., M.R.C.P. \\ J. N. SAOUR $\ddagger$ \\ M.D. \\ C. R. RICKETTS +
D.S.C. \\ B. J. Pollard* \\ B.Pharm. \\ S. M. HARDY* \\ S. P. Allison $\dagger$ \\ S.R.D. \\ M.D., M.R.C.P. \\ * Nottingham City Hospital, $\uparrow$ Nottingham General Hospital, and \\ $\ddagger M R C$ Industrial Injuries and Burns Unit, Birmingham Accident Hospital
}

\begin{abstract}
Summary
Fifteen patients with varying diagnoses were fed via nasogastric tubes for between 7 and 41 days using a feed consisting of Caloreen (a glucose polymer) and Albumaid (a beef serum hydrolysate) with vitamin and mineral supplements. The feed proved nutritionally adequate and relatively free of complications. Diarrhoea was seen only in those patients receiving antibiotics by the nasogastric route. Codeine phosphate abolished this symptom in all patients. The constant drip method of administration proved efficient and time saving. Unlike prepacked preparations, the feed could be varied in composition to suit the clinical situation. This was of particular advantage in the intensive care context. The feed was relatively inexpensive.
\end{abstract}

\section{Introduction}

Nasogastric tube feeding is used frequently in the hospital environment to provide nutrients, fluids and electrolytes to those patients unable to eat but whose gastrointestinal function is adequate. In many cases, little thought is given to the constitution or administration of such feeds, and they have achieved a certain notoriety from their commonly found tendency to produce diarrhoea (Peaston, 1967). Many of the prepacked 'elemental diets' are not only extremely expensive but, by virtue of the fact that they are ready mixed, lack the flexibility required in many intensive care situations. The present study forms part of an attempt to overcome the problems firstly of administration, secondly of nutritional adequacy and flexibility, thirdly of water and electrolyte control and lastly of complications.

Requests for reprints: Dr S. P. Allison, Nottingham General Hospital, Park Row, Nottingham NG1 6HA.

\section{Materials}

(1) Caloreen*

This is an electrolyte-free glucose polymer with a mean chain length of five glucose molecules. It is much less sweet than glucose, and being a polymer exerts only one-fifth the osmotic pressure in solution as the same weight of glucose. It seemed therefore less likely than glucose to produce diarrhoea. The freedom from electrolyte seemed advantageous in the intensive care context, since many of the patients had electrolyte disorders. Amounts of sodium and potassium, appropriate to the particular situation, could then be added. Caloreen is absorbed and metabolized as a glucose (Berlyne et al., 1969).

\section{(2) Albumaid $\dagger$}

This hydrolysate of beef serum provides $90 \mathrm{~g}$ of amino acids $/ 100 \mathrm{~g}$, in addition to some minerals, trace elements and vitamins. Essential amino acids comprise $41.9 \%$ of total amino acids and the pattern conforms well to the FAO/WHO Expert Group (1965) recommendations. Its electrolyte content is low (Table 1).

\section{(3) Additives (Table 1)}

Although Albumaid contains vitamins of the B group with some folic acid and $B_{12}$, additional water-soluble vitamins were given in the form of two crushed Ketovite tablets daily. Vitamins A, D, $B_{12}$ and choline were given as $5 \mathrm{ml}$ of Ketovite syrup. Additional trace elements were provided by $8 \mathrm{~g}$ of Mineral Mixture $\dagger$ per day. These doses of supplements follow the recommendations of Allan,

* Scientific Hospital Supplies Limited.

† Scientific Hospital Supplies Limited: Paines and Byrne Limited. 
TABLE 1. Composition of nasogastric feed for a $60-\mathrm{kg}$ man

\begin{tabular}{|c|c|c|c|c|c|c|c|c|c|c|c|}
\hline & \multirow[b]{2}{*}{ kcal } & \multirow{2}{*}{$\begin{array}{l}\text { Nitrogen } \\
\text { (g) }\end{array}$} & \multicolumn{9}{|c|}{ Minerals (mmol) } \\
\hline & & & $\mathrm{Na}$ & $\mathbf{K}$ & $\mathrm{Ca}$ & $\mathbf{M g}$ & $\mathrm{Fe}$ & $\mathrm{Zn}$ & $\mathrm{Cl}$ & $\mathrm{SO}_{4}$ & $\mathrm{PO}_{4}$ \\
\hline Caloreen $600 \mathrm{~g}$ & 2400 & - & 0 & $\mathbf{0}$ & & & & & & & \\
\hline Albumaid $60 \mathrm{~g}$ & - & 8 & 26 & 3 & $4 \cdot 5$ & $7 \cdot 5$ & 0.1 & 0.02 & 60 & $0 \cdot 16$ & $6 \cdot 3$ \\
\hline $\begin{array}{l}\text { Mineral Mixture } \\
\text { Ketovite Tablets } 2 \\
\text { Ketovite Syrup } 5 \mathrm{ml}\end{array}$ & - & - & 14 & 17 & $16 \cdot 5$ & $3 \cdot 2$ & 0.07 & 0.013 & 4 & 3.28 & $15 \cdot 2$ \\
\hline Total & 2400 & 8 & 40 & 20 & 21 & $10 \cdot 7$ & $0 \cdot 17$ & 0.013 & 64 & 3.44 & $21 \cdot 5$ \\
\hline
\end{tabular}

If the feeding period $>7$ days, essential fatty acids provided by 1 egg yolk. Water is added as appropriate-usually $1500-$ $2500 \mathrm{ml}$. Additional electrolytes are added as necessary in the form of $\mathrm{NaCl}$ or $\mathrm{KCl}$. The mineral mixture also contains traces of the elements $\mathrm{Cu}, \mathrm{Mn}, \mathrm{Mo}, \mathrm{Al}$ and $\mathrm{I}$.

Mason and Moss (1973), who used a similar regime in the management of cystic fibrosis in children. Where nasogastric feeding was continued for more than 7 days, essential fatty acids were provided by the addition of one egg yolk to the feed.

\section{(4) Composition and administration}

The feed composition for an individual weighing $60 \mathrm{~kg}$ is shown in Table 1. The dose of Caloreen used was $10 \mathrm{~g}$ and that of Albumaid $1 \mathrm{~g} / \mathrm{kg}$ body-weight. The feed was made up each day in the pharmacy, diet kitchen or ward with $1500-2500 \mathrm{ml}$ of water according to the individual patient's fluid requirements. The mixture was then placed in screw-top i.v. type bottles and carefully labelled as to contents, to render them easily distinguishable from bottles containing i.v. fluids. For the first $\mathbf{2 4} \mathrm{hr}$, a mixture of milk and water was delivered via an 8FG Ryle's tube into the stomach. Aspiration every $4 \mathrm{hr}$ ensured that the stomach was emptying normally, obviating the risk of vomiting and aspiration into the lungs. The feed was then introduced at one-half strength and increased to full strength over 2 days. It was given by constant drip throughout the $24 \mathrm{hr}$. A formal work study was carried out to assess the possible time saved by this method of administration.

\section{Methods}

Patients

Fifteen patients of varying diagnosis were studied (Table 2) for periods ranging from 7 to 41 days. Eight additional patients were involved in the work study.

\section{Clinical measurements}

The patients were weighed daily and examined frequently for the presence of oedema. Careful fluid balance charts were recorded. Stool charts were kept to record the number and character of the stools.

\section{Metabolic measurements}

The urine was tested regularly by the clinitest method and the blood glucose estimated daily by the auto-analyzer glucose oxidase technique. If there was more than $0.5 \%$ glycosuria or the blood glucose rose above $10 \mathrm{mmol} / 1$ then insulin was administered on a sliding scale.

In three patients, in whom glycosuria occurred, the urine was subjected to chromatography by gel filtration and paper chromatography. This was in order to exclude the presence of any carbohydrate polymer. The same samples were also estimated for amino acids by paper chromatography to exclude excessive losses of administered Albumaid. $\mathrm{Hb}$, plasma urea, $\mathrm{Na}, \mathrm{K}, \mathrm{HCO}_{3}$ and serum osmolality estimations were performed three times weekly. Sequential 24-hr urine collections were made and estimated for urea, $\mathrm{Na}, \mathrm{K}$ and osmolality. From the urine urea excretion, approximate nitrogen balances were calculated by the method of Lee (1974).

TABle 2. Patients studied

\begin{tabular}{cl}
\hline Number & \multicolumn{1}{c}{ Diagnosis } \\
\hline 7 & Surgery for cancer of mouth \\
2 & Crushed chest (on ventilator) \\
3 & Head injury \\
1 & Head injury and crushed chest (on ventilator) \\
1 & Post-operative collapse (on ventilator) \\
1 & Respiratory failure (on ventilator) \\
& 12 survived $\quad 3$ died \\
\hline
\end{tabular}

\section{Work study}

The time taken to prepare and administer tube feeds by two different methods was compared. Method I The previously used mixed ingredient feed (milk, eggs, etc.) was made up in the diet kitchen and sent up to the ward in jugs to be syringed down the nasogastric tube at intervals during the day. Method II The Caloreen/Albumaid feed was measured out by the diet kitchen cooks and sent dry in sachets to the ward. The nurses then mixed the powder with water in $500 \mathrm{ml}$ drip bottles and allowed each bottle to drip via an i.v. type giving set into the 
nasogastric tube over a period of 4-6h. Each part of the process was timed separately on eight different occasions.

\section{Statistical analysis}

The results were examined using standard statistical techniques. The differences between initial and final biochemical values were analysed using a paired $t$-test.

\section{Results}

\section{(1) Weight changes}

In twelve patients the weight-gain or loss over the period of feeding did not exceed $2 \mathrm{~kg}$. One patient gained $11.5 \mathrm{~kg}$ owing to the injudicious administration of large volumes of i.v. saline leading to oedema. Two patients lost $3 \mathrm{~kg}$ over the first few days of feeding. They started with oedema which was treated with a single dose of diuretic and limitation of the sodium content of the feed.

\section{(2) Nitrogen balances (ten patients)}

The mean daily nitrogen balance was -0.42 $\pm 1.8 \mathrm{~g}$ (1 s.d.).

\section{(3) Biochemistry}

There were no significant changes in serum $\mathrm{Na}^{+}$, $\mathrm{K}^{+}$, urea or albumin concentrations or in serum osmolality. Chromatography of the urine in three patients showed that, apart from a trace of an unidentified sugar, all the carbohydrate appearing in the urine was glucose. Small amounts of amino acids were found in the urine, insignificant from a nutritional point of view.

\section{Haematology}

Four of the patients required blood transfusions. In those patients not transfused, there were no consistent changes in haemoglobin concentrations or in blood counts or films.

\section{Insulin requirements (Table 4)}

The more severely ill patients were intolerant of the large carbohydrate load and required insulin treatment to maintain normoglycaemia. This is consistent with previous work showing that glucose intolerance is proportional to the severity of injury (Allison, Hinton and Chamberlain, 1968). Ten patients required no insulin. In these, the degree of trauma was relatively small.

\section{Work study}

The results are shown in Table 3. The constant drip method of administration using an artificial tube feed saved $1 \mathrm{hr}$ of nurse/dietician time daily.

TABLE 4. Insulin requirements to maintain blood glucose at $5-10 \mathrm{mmol} / \mathrm{l}$

\begin{tabular}{lc}
\hline \multicolumn{1}{c}{ Diagnosis } & Sol. insulin units/24 hr \\
\hline 1 post-operative collapse & $60-120$ \\
2 crushed chest & $40-120$ \\
1 head injury and crushed chest & $40-80$ \\
1 cancer of mouth & 20 for 3 days only \\
3 head injury & 0 \\
1 respiratory failure & 0 \\
6 cancer of mouth & $0^{*}$
\end{tabular}

* One patient was an insulin-dependent diabetic. Her insulin requirements did not change during the period of feeding.

\section{Complications}

(a) Diarrhoea. This was deliberately given a very strict definition, i.e. more than one loose motion daily. By this criterion, seven of the patients suffered from diarrhoea. However, six of these were being treated with broad spectrum antibiotics via the nasogastric route. Of the eight patients who did not develop diarrhoea, none was receiving antibiotics by the nasogastric route, although two were receiving parenteral antibiotics. The symptom was easily controlled in all cases by the addition of codeine phosphate syrup (30-150 mg daily) to the tube feed.

(b) Nausea. This was experienced by a minority of patients and was usually transient. It was invariably alleviated by metoclopramide or prochlorperazine.

TABLE 3. Comparison of times involved in preparation and administration of tube feeds by Methods I and II. Values are expressed as the means of at least eight separate timings

\begin{tabular}{lcc}
\hline & Method I & Method II \\
\hline $\begin{array}{l}\text { Preparation in diet kitchen } \\
\text { Preparation in ward kitchen } \\
\text { Total preparation }\end{array}$ & $10 \mathrm{~min} 20 \mathrm{sec}$ & $3 \mathrm{~min} 40 \mathrm{sec}$ \\
$12 \mathrm{~min}$ & $15 \mathrm{~min} 40 \mathrm{sec}$ \\
$\begin{array}{l}\text { Each nurse visit to patient (for feeding purposes) } \\
\text { Setting up drip initially }\end{array}$ & $10 \mathrm{~min} 20 \mathrm{sec}$ & $4 \mathrm{~min} 45 \mathrm{sec}$ \\
$\begin{array}{l}\text { No. of nurse visits necessary per day } \\
\text { Total administration time }\end{array}$ & $9 \mathrm{~min}$ & $2 \mathrm{~min} 20 \mathrm{sec}$ \\
$\begin{array}{l}\text { Time requirement for preparation and administration, per patient } \\
\text { Tim }\end{array}$ & $100 \mathrm{~min} 20 \mathrm{sec}$ & $46 \mathrm{~min} 30 \mathrm{sec}$ \\
\hline
\end{tabular}




\section{Discussion}

These results show that it is possible to feed both critically ill and surgical patients by the nasogastric route for long periods, and to maintain them in a satisfactory nutritional and metabolic state, free of the usual complications of tube feeding. Although the methods used for assessing nutrition in this study are essentially crude, they are sufficient indication of nutrition in most patients. As has been shown, weight can be dramatically altered over short periods by changes in fluid balance. It would be difficult to argue, however, that a patient was not in a satisfactory nutritional state, who suffered no change in weight or in other parameters after 41 days of tube feeding.

Diarrhoea has been the scourge of tube feeding techniques in the past. This may be due to several factors. The purgative effect of solutions of high osmolality is well known. In this respect, Caloreen represents an advance over glucose. Additional causes of diarrhoea may be fermentation of sugar which reaches the large bowel, and possibly fat intolerance in ill patients. Hindmarsh and Clark (1973) have suggested that lactose intolerance could have been one of the factors responsible for the diarrhoea associated with the jejunostomy feeds of Masterton, Dudley and Macrae (1963). In the present study the chief factor causing diarrhoea appeared to be the administration of broad-spectrum antibiotics by the nasogastric route. The symptom was reliably controlled using codeine phosphate.

No problems of serum hyperosmolality were encountered. So simple are the precautions needed to prevent this that it must be regarded as inexcusable to allow this complication to occur. Clinitest estimations on urine and a daily blood glucose measurement ensure that hyperglycaemia can be observed and treated. A high urea production rate and hence a rise in blood urea is prevented by giving an adequate ratio of calories to $\mathrm{g}$ of nitrogen, i.e. at least 200:1. In this study, a ratio of 280:1 was given. An adequate water intake is an obvious precaution.

Recent, unpublished, work by Ricketts et al. on the i.v. infusion of Caloreen has shown that successive urine samples contain more of the smaller molecules. This is the opposite of what would be expected on a hypothesis of ultrafiltration by the kidney. It follows from the absence of Caloreen molecules in the urine of the patients in this study, that this substance is all absorbed as glucose through the action of enzymes normally present in the small intestine.

Although the desirable intake of vitamins and minerals in healthy subjects has been fairly well agreed, the optimum intake of these substances during illness is not clearly established. The achievement of an ideal mineral combination is further complicated by the many factors which affect the absorption of metal ions. The amounts used in this study were therefore arbitrary and based on the experience of Allan et al. (1973) who used a similar regime as a nutritional supplement for children with cystic fibrosis. The quantities of calcium, magnesium and phosphate contained in the feed approximate to those recommended by the National Academy of Sciences, Washington (1974). Fatty acid deficiency has been described from patients receiving long term i.v. feeding with carbohydrate as the sole calorie source (Collins et al., 1971). For this reason one egg yolk was given daily where feeding was continued for more than 7 days. Fat is otherwise not an essential constituent of the diet, although it remains a useful concentrated source of calories. Since the increased protein catabolism which accompanies illness or injury is related to the increased demand for new glucose (Kinney et al., 1970), it may be argued that carbohydrate is likely to be more protein-sparing than fat in such patients. Recent evidence from Wilmore and his colleagues (personal communication) suggests that this hypothesis may be correct and lends further justification to the use of carbohydrate as the main source of calories in this study.

For routine management of tube feeds, most of the measurements described in this paper are unnecessary. Measurement of the following are desirable in most cases-weight, observation for oedema, accurate fluid balance charts, twice weekly serum urea, electrolytes, urine test for sugar and occasional blood sugar estimations. The regime described here was primarily designed for use in the intensive care context. For routine tube or supplementary feeding on the general ward, an even less expensive and more convenient regime has been used, mixing Caloreen and Complan in the proportions $3: 2$ by weight. There appears to be no case for the use of prepacked elemental diets while they remain so expensive. A comparison of tube feed costs has recently been published (Allison and Woolfson, 1975). The making up of tube feeds from raw materials has another advantage as well as cheapness over the use of pre-packed preparations. It enables the doctor to cope with all the metabolic problems encountered in critically ill patients by varying the composition to suit the clinical situation. The constant drip method of infusion is possibly more satisfactory clinically, but is certainly better administratively, since it saves nursing time and ensures a more reliable delivery of the feed to the patient. This regime also has advantages over the liquefied ward diets sometimes used. Its relatively low viscosity allows the use of the constant drip method of administration and its known electrolyte content allows more accurate balances to be kept. The nursing time involved in tube feeding has been reduced further since this study was carried out. Standard one-litre Winchester 
bottles are now used which only require changing every 8-12 hr. Avon Plastics have adapted their bladder washout giving sets to be used with this system. These sets will only fit into the nasogastric tube and cannot therefore be connected by mistake to an i.v. cannula.

\section{Acknowledgments}

We thank the members of our Pharmacy Departments and the nursing staff of our hospitals for all their help and support with this study. We also thank Dr Geoffrey Walker, Dr John Foote and their departments for the biochemical estimations, and our colleagues, particularly Mr Malcolm Deane, for allowing us to study their patients.

\section{References}

Allan, J.D., Mason, A. \& Moss, A.D. (1973) Nutritional supplementation in treatment of cystic fibrosis of the pancreas. American Journal of Diseases of Children, 126, 22.

Allison, S.P., Hinton, P. \& Chamberlain, M.J. (1968) Intravenous glucose tolerance, insulin and free fatty acid levels in burned patients. Lancet, ii, 1113.

Allison, S.P. \& Woolfson, A.M.J. (1975) Elemental diets. Lancet, ii, 874.
Berlyne, G.M., Booth, E.M., Brevis, R.A.L., Mallick, N.P. \& Simons, P.J. (1969) A soluble glucose polymer for use in renal failure and calorie deprivation states. L.ancet, i, 689.

Collins, F.D., Sinclair, A.J., Coats, D.A. \& Maynard, A.T. (1971) Plasma lipids in human linoleic acid deficiency. Nutrition and Metabolism, 13, 150.

FAO/WHO EXPERT Group (1965) Protein Requirements. F.A.O. Nutrition Meeting Report Series, No. 37.

Hindmarsh, J.T. \& ClarK, R.G. (1973) New jejunostomy feed. British Medical Journal, 3, 609.

KINNEY, J.M., DUKE, J.H., LONG, C.L. \& GuMP, F.E. (1970) Design of tube feeds for surgical patients. Journal of Clinical Pathology, 23 (Suppl. 4), 65.

LeE, H.A. (1974) In: Parenteral Nutrition in Acute Metabolic Illness, p. 314. Academic Press, London and New York.

Masterton, J.P., Dudley, H.A.F. \& Macrae, S. (1963) Plasma lipids in human linoleic acid deficiency. British Medical Journal, 2, 909.

National ACademy of Sciences. Washington (1974) Tissue fuel and weight loss after injury.

National ACademy of Sciences, Washington (1974) Tissue fuel and weight loss after injury. In: Recommended Dietary Allowances.

Peaston, M.J.T. (1967) Maintenance of metabolism during intensive patient care. Postgraduate Medical Journal, 43, 317. 